\title{
Lope de Vega y el descubrimiento de la verdad en la comedia nueva
}

\author{
Ismael LÓPEZ MARTÍN \\ Universidad de Extremadura \\ ismael@unex.es
}

\begin{abstract}
RESUMEN
En este artículo se analiza el tratamiento que tuvo el mecanismo de descubrimiento de la verdad dramática en los principales tratados teóricos y poéticos del Siglo de Oro, en su mayoría italianos. El origen de este recurso se encuentra en la Poética de Aristóteles, y este es el punto de partida para la elaboración de un estudio comparativo de su concepto, tipología y aplicación al género de la comedia nueva y, más concretamente, a algunas comedias seleccionadas de frey Lope Félix de Vega Carpio. Para observar el tratamiento que hace el dramaturgo de este particular se trabaja con tres piezas que se adscriben a la primera etapa de la producción lopesca: Los hechos de Garcilaso de la Vega y Moro Tarfe, Las ferias de Madrid y La serrana de La Vera.
\end{abstract}

Palabras clave: Descubrimiento de la verdad; Lope de Vega; teatro barroco.

\begin{abstract}
This article discusses the treatment that the mechanism of the discovery of the dramatic truth had in the main theoretical and poetry essays of the Golden Age, mostly Italians. The origin of this resource is in the Aristotle's Poetics, and this is the starting point for the development of a comparative study of its concept, types and application to the new comedy genre and more specifically, to some selected comedies written by frey Lope Félix de Vega Carpio. To note the treatment that the playwright makes, we work with three plays that are assigned to the first period of Lope's production: Los hechos de Garcilaso de la Vega y Moro Tarfe, Las ferias de Madrid and La serrana de La Vera.
\end{abstract}

Keywords: Discovery of the truth; Lope de Vega; baroque theater.

Sumario: 1. Introducción, 2. El descubrimiento de la verdad en la Poética de Aristóteles, 3. El descubrimiento de la verdad en los comentaristas del Siglo de Oro, 4. Miradas lopescas del descubrimiento de la verdad, 5. Hacia una conclusión. 


\section{Introducción}

Para conocer la evolución del concepto de agnición, sus características y tipología, desde Aristóteles hasta el siglo XVII, se han seleccionado las siguientes poéticas y tratados teóricos: Poética, de Aristóteles (siglo IV a. C.); Epistula ad Pisones o Ars poetica, de Quinto Horacio Flaco (siglo I d. C.); In librum Aristotelis de Arte Poetica explicationes, de Francesco Robortello (1548); Discorsi intorno al comporre de i romanza, delle Comedie, e delle Tragedie, e di altre maniere di Poesie, de Giovambattista Giraldi Cinthio (1554); De poeta, de Antonio Sebastiani Minturno (1559); Poetices libri septem, de Giulio Cesare Scaligero (1561); L'arte poetica, de Antonio Sebastiani Minturno (1563); Poetica d'Aristotele, de Ludovico Castelvetro (1570); Annotationi nel libro della Poetica d'Aristotele, de Alessandro Piccolomini (1572); Discorsi dell'arte poetica e del poema eroico, de Torquato Tasso (1587); Philosophia antigua poetica, de Alonso López Pinciano (1596); Arte nuevo de hacer comedias en este tiempo, de Lope Félix de Vega Carpio (1609); Tablas poéticas, de Francisco Cascales (1617); Poética de Aristóteles traducida de latín, de Juan Pablo Mártir Rizo (1623), y Nueva idea de la tragedia antigua o Ilustración última al libro singular de Poética de Aristóteles Stagirita, de Jusepe Antonio González de Salas (1633).

Como puede observarse, más allá de las teorías expuestas en la Antigüedad, los comentaristas neoaristotélicos del siglo XVI eran, eminentemente, italianos; sin embargo, sobre todo desde López Pinciano, a finales de esa centuria, los teóricos españoles se incorporaron a esta tradición, incluido el Fénix de los Ingenios.

\section{EI descubrimiento de la verdad en la Poética de Aristóteles}

El género dramático que analiza Aristóteles en la Poética es la tragedia, y parte de los seis elementos constituyentes de las obras que se adscriben a él: fábula

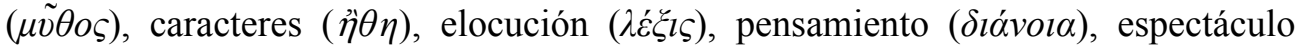

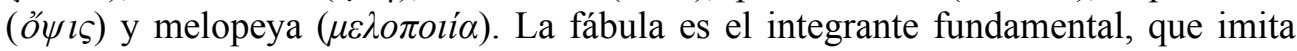
las acciones, simples o complejas, del mundo real. Esas acciones, que implican cambio de fortuna, hacen que las fábulas también sean simples o complejas. Cuando la acción es simple, la fortuna cambia, desde la fábula, sin peripecia ni anagnórisis; cuando es compleja, sin embargo, cambia con peripecia, con anagnórisis o con las $\operatorname{dos}^{1}$.

Aristóteles explica que la anagnórisis es el proceso que se da dentro de la fábula de la tragedia y que, con peripecia o no, provoca el reconocimiento de un determinado personaje o situación. Es "un cambio desde la ignorancia al conocimiento"2.

Más adelante propone una tipología de la anagnórisis basada en la naturaleza de los reconocimientos.

\footnotetext{
${ }^{1}$ Los cambios de fortuna responderán siempre a la necesidad o verosimilitud de la fábula.

${ }^{2}$ Aristóteles (1988), p. 164.
} 


\section{El descubrimiento de la verdad en los comentaristas del Siglo de Oro}

La noción horaciana de producir sorpresa en el público y conmoverlo ${ }^{3}$ es tomada por Francesco Robortello en 1548: "Cuantas veces cambiamos de parecer, de opinión o de idea se produce cierto movimiento, pues no hay cambio alguno sin movimiento" ${ }^{4} \mathrm{o}$, más adelante, en

los poetas necesitaron utilizar este recurso para provocar mayor admiración, esto es, lo maravilloso (de lo que hemos hablado anteriormente), en aras de deleitar los ánimos de los espectadores. Pero hay otra anagnórisis, producida sin retardamiento alguno, en la que desde el principio alguien contempló algún rostro. ${ }^{5}$

Robortello prácticamente parafrasea a Aristóteles cuando ofrece su definición de anagnórisis:

Es también anagnórisis el cambio que se produce de la ignorancia al conocimiento, pues quien conoce algo mediante anagnórisis adquiere conocimiento de aquello que ignoraba. ${ }^{6}$

Sin embargo, mientras el Estagirita únicamente escribió que la anagnórisis debía responder ante los criterios de verosimilitud o necesidad y, en el mejor de los casos, proceder directamente del desarrollo de la fábula, Robortello da un paso más e infiere que algún tipo de agnición ha de producirse durante toda la obra, progresivamente:

Pues esta que nos ocupa, de la que hablamos, la anagnórisis poética, se produce progresivamente, la otra, de manera inmediata, ya que los poetas provocan su anagnórisis a partir de señales latentes que no captan los sentidos de inmediato; así pues, se produce después de un largo intervalo de tiempo hablando. ${ }^{7}$

En cuanto al comentario que realiza sobre la tipología de la anagnórisis, expuesta por Aristóteles, Robortello se limita a describirla y a ilustrarla con ejemplos literarios, en la mayoría de los casos coincidentes con los del filósofo heleno. Sin embargo, muestra en sus caracterizaciones que es un ferviente defensor de la verosimili-

\footnotetext{
${ }^{3}$ Horacio (1998), p. 103: "No basta con que los poemas sean formalmente perfectos: deben ser encantadores y conducir el ánimo del oyente adonde quieran. Igual que los rostros humanos sonríen cuando ven reír, también así lloran cuando ven llorar. Si quieres que yo llore, primero has de sufrir tú en persona; entonces, tus infortunios, Télefo o Peleo, me conmoverán".

${ }^{4}$ F. Robortello (1548), p. 108.

${ }^{5}$ F. Robortello (1548), p. 109.

${ }^{6}$ F. Robortello (1548), p. 108.

${ }^{7}$ F. Robortello (1548), p. 109.
} 
tud, que puede apreciarse, sobre todo, cuando trata de los dos primeros tipos de agnición: el que se produce por señales y el que nace del arbitrio del autor, del que destaca el peligro que conlleva, pues puede no ajustarse, precisamente, a la verosimilitud de la fábula. En este sentido, la novedad de Robortello es que incluye, como sexto tipo de agnición con respecto a la propuesta de Aristóteles, la que se produce por verosimilitud, lo cual será criticado, posteriormente, por Piccolomini.

Recuérdese que el Estagirita únicamente trataba de la tragedia en su Poética, al menos en el texto que ha llegado hasta nosotros, pero Robortello da un paso importante para la teoría de la dramaturgia y que tendrá mucha influencia posterior: aplica todo lo que Aristóteles afirmaba de la tragedia también a la comedia y, por ende, incluidos sus comentarios: "Lo que utilizan los poetas trágicos lo utilizan también los cómicos" $"$.

La extensión de los preceptos a la comedia no fue fácil, puesto que se estaba afirmando algo que el Estagirita no escribió. Así, Cinthio sí que cree, como Robortello, que pueda existir la anagnórisis en la comedia ${ }^{9}$ :

No son, sin embargo, la agnición y la peripecia (tomándola en sentido amplio) así solo de la tragedia como ambas propias de la comedia. ${ }^{10}$

Mientras que Robortello piensa que el recurso, sin más, también está presente en la comedia, Cinthio considera que, cuando aparece en este género, no conlleva un cambio de fortuna ${ }^{11}$, en contra de lo que después postuló Minturno, quien se pregunta si "¿acaso la expectación no va unida con la anagnórisis y con la equivocación inesperada en el Heautontimorúmeno?"12. Seguidamente, con un ejemplo de esta obra de Terencio que cita, retoma la idea de la admiratio que la anagnórisis debía producir, aunque no la aplica al público, como Horacio y Robortello, sino a los mismos personajes de la comedia. Minturno volvió a plasmar los conceptos del cambio de fortuna y de admiratio en una obra posterior, L'arte poetica, en la que destacó una división de anagnórisis en "de persona" y "de cosa":

Y por reconocimiento entiendo, como la propia voz indica, el reconocimiento de alguna persona, de cuyos actos se tratan, que se dirigen a la benevolencia o al odio. [...] Se reconocen todavía muchas, y especialmente, las que alguno ha

\footnotetext{
${ }^{8}$ F. Robortello (1548), p. 109.

${ }^{9}$ Considera, no obstante, que, según se trate de uno u otro género, la agnición es diferente.

${ }^{10}$ G. G. Cinthio (1554), p. 241.

${ }^{11}$ Aristóteles creía necesario un cambio de fortuna, aunque en su obra únicamente se trata de la tragedia.

${ }^{12}$ A. S. Minturno (1559), p. 284.
} 
hecho o sufrido. Y ese reconocimiento es el más admirable acontecimiento, al cual sigue lo maravilloso, muy lejos de nuestros pensamientos. ${ }^{13}$

Dos años antes, en 1561, Scaligero había establecido esa clasificación de la agnición, explicando que existía una "de persona" y una "de situación": "personas y situaciones desconocidas se conocen por azar, señales o augurios"14.

Ludovico Castelvetro fue uno de los primeros tratadistas que cuestionó, ya en 1570, algunos aspectos de la teoría de Aristóteles, proponiendo sus nuevos esquemas y clasificaciones, incluso con plena consciencia de ello:

Veo que se podría hacer una división más diligentemente, y más completa, y por no alejarse del pensamiento de Aristóteles, no nos fatiga hacerla de otra manera. ${ }^{15}$

Además, criticó al Estagirita que no dedicara el tiempo suficiente a explicar las distintas clases de anagnórisis para la mejor comprensión del concepto. Castelvetro propuso una clasificación de agnición atendiendo a los principales ejes del reconocimiento: las personas, los hechos y las cosas.

Alessandro Piccolomini fue un defensor a ultranza de las ideas de Aristóteles, fue un purista, y uno de sus empeños era combatir a los autores italianos que interpretaron mal al Estagirita, y tal hace con Robortello:

Y, a pesar de que, tal vez, podría apoyar la idea de Robortello, sin embargo, no hay que juzgarla razón válida porque salva lo dicho por Aristóteles: diciendo que entiende Aristóteles de la peripecia que contiene cambio de la felicidad a la infelicidad, como puede verse; él no toma rápidamente ejemplo de la tragedia de Edipo. Y hecha así entiende la peripecia Robortello: que el reconocimiento se pueda separar, pero no ya de la peripecia entendida en su propio significado. Esta exposición es para salvar, al mismo tiempo, las palabras de Aristóteles, y la verdad de la cosa según él, esto es, que no pueda encontrarse reconocimiento sin peripecia alguna. ${ }^{16}$

Otra corrección que se vio en la necesidad de hacer fue en relación con la tipología de anagnórisis que había planteado Robortello, quien incluyó una sexta clase no descrita, como tal, en la obra aristotélica: la que se producía desde la verosimilitud. La solución que propone Piccolomini pasa porque la verosimilitud es deseable en todos los tipos de reconocimiento:

\footnotetext{
${ }^{13}$ A. S. Minturno (1725), p. 43.

${ }^{14}$ G. C. Scaligero (1561), p. 146.

${ }^{15}$ L. Castelvetro (1978), p. 453.

${ }^{16}$ A. Piccolomini (1575), p. 170.
} 
Pero, al final, me resuelvo a creer que esta no se puede decir ni quinta, ni sexta, ni ninguna denominación numeral con las otras; sino más bien el modo más perfecto de usar todas las otras clases. ${ }^{17}$

Tasso no fue tan condescendiente con Aristóteles y, al igual que Robortello y Castelvetro, se atrevió a cuestionar algunas de sus afirmaciones, de las cuales destacan dos por su relación con el recurso de la anagnórisis. Recuérdese que los tres pilares fundamentales sobre los que se asentaban los objetos del reconocimiento eran las personas, los hechos y las cosas; pues bien, para él, "la agnición del hecho es más propia de los oradores que de los poetas, de quienes es auténtica la agnición de persona"18.

La influencia de tratadistas italianos como Piccolomini se deja ver en la obra de Pinciano, para quien la "agnición, o reconocimiento se dize una noticia subita y repentina de alguna cosa: por la qual venimos en gran amor; o en gran odio de otro" 19 , afirmación en la que opina que toda anagnórisis va acompañada de peripecia. Pinciano recuerda la clasificación que hace Aristóteles, de la que excluye la que se produce por paralogismo (quinta especie según el Estagirita): "La una [...] se haze y exercita con señales [...], la segunda [...] es hecha del Poeta, $[\ldots]$ la tercera es por la memoria hecha: y la quarta por silogismo, o discurso" ${ }^{20}$.

Pero el comentarista español, siguiendo la tradición de los italianos, propone una tipología de la anagnórisis según su administración, basada en la idea platónica de las tres potencias del alma: el descubrimiento de la verdad por medio del discurso o del entendimiento, de la memoria y de la voluntad ${ }^{21}$.

Los italianos fueron los comentaristas neoaristotélicos más numerosos y destacados del siglo XVI, y su influencia se dejó ver en algunos españoles como López Pinciano, uno de los más significativos. Con las ideas expuestas se llega a Lope de Vega y su Arte nuevo de hacer comedias en este tiempo, publicado en 1609, donde el dramaturgo recoge la tradición y la sintetiza en su aspecto fundamental: "Engañe siempre el gusto, y donde vea/que se deja entender alguna cosa,/dé muy lejos de aquello que promete ${ }^{22}$. El Fénix propone que en las comedias sucedan cambios, de cualquier tipo, para sorprender al público ${ }^{23}$, sin referirse explícitamente a la anagnórisis, aunque creemos que la insinúa. Por otro lado, cabe decir que no entra en ninguno de los tres principales debates que generaron los tratadistas italianos: que la agnición conlleve o no peripecia, cuál es su tipología y qué tipo de reconocimiento es mejor.

\footnotetext{
${ }^{17}$ A. Piccolomini (1575), p. 240.

${ }^{18}$ T. Tasso (1964), p. 142.

${ }^{19}$ A. López Pinciano (1596), p. 175.

${ }^{20}$ A. López Pinciano (1596), p. 177.

${ }^{21}$ A. López Pinciano (1596), pp. 178-181.

${ }^{22}$ L. F. de Vega Carpio (2006), p. 147.

${ }^{23}$ Incluyendo, entre otros, el engaño y el hablar equívoco.
} 
Muy escueto es también el tratamiento que del recurso hace Francisco Cascales en sus Tablas poéticas, donde únicamente explica que "simple es la cómica fábula que no tiene reconocimientos" 24 , como ya adelantó Aristóteles.

Puede destacarse, también, a Juan Pablo Mártir Rizo, quien se dedicó a definir la agnición como "transmisión de inteligencia de no saber alguna cosa a venir en conocimiento de la misma" 25 y a explicar la clasificación que del recurso propugnó Aristóteles, incorporando ejemplos de Giovanni Boccaccio ${ }^{26}$, como hizo Castelvetro. Además, Mártir Rizo explicó cuáles eran las características que debía poseer una "comedia perfecta":

Debe una comedia perfecta ser de una sola acción simple, ridiculosa, de personas particulares con mediocridad de buenas y malas por algún yerro o defecto de nuestra humana naturaleza, de ignorancia, o simplicidad, por transmutación de fortuna de la adversidad a la prosperidad con peripecia y con agnición. ${ }^{27}$

Por último, a pesar de ser más tardío en el tiempo, debemos mencionar a González de Salas, un destacado comentarista español que, en 1633, dos años antes del fallecimiento de Lope de Vega, ya no presta demasiada atención a las discusiones de nomenclatura y se limita a expresar en lengua castellana la doctrina de Aristóteles, aunque con algunas incorrecciones, como en el caso de los tipos de anagnórisis:

La primera es por algunas señales impresas de la misma Naturaleça en los cuerpos humanos [...]. La segunda es por señal adquirida de algun suceso [...]. La tercera specie es por la Memoria [...]. La quarta specie que pone, es por Silogismo, o Raciocinacion [...]. Finalmente la quinta specie de conocimientos es por Engaño, o Paralogismo. ${ }^{28}$

Como puede observarse, González de Salas divide el primer tipo aristotélico de agnición (por señales) en dos. El Estagirita entendió estos dos tipos del tratadista español como subdivisiones del primero. Salas, además, obvia la segunda especie de anagnórisis que cita Aristóteles: la que se produce por arbitrio del autor.

\section{Miradas lopescas del descubrimiento de la verdad}

El descubrimiento de la verdad en las comedias, esto es, la anagnórisis, fue un recurso fundamental y muy utilizado por Lope de Vega en la práctica totalidad de

\footnotetext{
${ }^{24}$ F. Cascales (1617), p. 377.

${ }^{25}$ F. Sánchez Escribano y A. Porqueras Mayo (1971), p. 235.

${ }^{26}$ F. Sánchez Escribano y A. Porqueras Mayo (1971), pp. 235-236.

${ }^{27}$ F. Sánchez Escribano y A. Porqueras Mayo (1971), p. 243.

${ }^{28}$ J. A. González de Salas (1633), pp. 37-38.
} 
su producción dramática. En las líneas siguientes se incluyen algunos ejemplos de su utilización en tres obras del Fénix: Los hechos de Garcilaso de la Vega y Moro Tarfe, Las ferias de Madrid y La serrana de La Vera.

Lope propuso en el Arte nuevo que la acción "dé muy lejos de aquello que promete", de lo que podemos inferir que el cambio en las situaciones, incluido el paso del desconocimiento al conocimiento, ha de retrasarse lo más posible con el fin de generar expectación en el espectador. Por ello, aunque bien pudiera entenderse que es al final de las comedias cuando se producen, si es el caso, las verdaderas agniciones, creemos, sin embargo, que el recurso es una herramienta mucho más potente. No pueden obviarse otras anagnórisis que se producen en las comedias, al comienzo o al final de las jornadas, por ejemplo. Cumplen la misma función que las que se suceden al cierre de las obras, esto es, iluminar alguna escena, personaje o acción que permanecen ocultos a los ojos de otros personajes o, incluso, del público.

La inclusión de las anagnórisis no suele ser casual ${ }^{29}$, aunque pueden encontrarse ejemplos de agniciones intrascendentes al finalizar, por ejemplo, la segunda jornada de Los hechos de Garcilaso de la Vega y Moro Tarfe, en el momento en que Leocán engaña a Tarfe y dice que en la habitación se encontraba Gazul, su enemigo, lo que propicia el ataque y el descubrimiento del engaño de Leocán, pues se trataba de una mujer, Alhama, con quien se casa el moro Tarfe ${ }^{30}$.

En las distintas clasificaciones que se han propuesto, el descubrimiento de la verdadera identidad de un personaje es uno de los tipos más repetidos de anagnórisis. Una agnición personal se produce cuando la identidad objeto de descubrimiento está oculta por desconocimiento, sin más, por parte del personaje destinatario de la anagnórisis o por un desconocimiento producido mediante engaño u ocultación del objeto por sí mismo o por el agente de la anagnórisis. Es decir, un personaje A (destinatario) puede desconocer la verdadera identidad de un personaje B (objeto) porque no la sabe, sin más, o porque el mismo personaje $\mathrm{B}$ o un personaje $\mathrm{C}$ (agente) se la ocultan o le engañan con una identidad falsa u obviándola.

Al final de la jornada primera de Las ferias de Madrid, Alberto está hablando mal de su mujer ante ella misma, Eufrasia, que está disfrazada. No puede aguantar más y ella misma se descubre, con la sorpresa del marido. Además, la criada Teodora también se quita el disfraz y deja de utilizar el ficticio nombre de Clara. Como puede verse, la ocultación de la verdadera identidad se ve reforzada por los procedimientos del disfraz y del cambio de nombre:

${ }^{29}$ Recuérdese que las comedias solían formar parte de las denominadas "fiestas barrocas", que duraban varias horas. Se representaba cada jornada de forma aislada, pues se intercalaban, entre ellas, algunas piezas de teatro breve: jácaras, entremeses o bailes. La inclusión de anagnórisis al final de las jornadas, e incluso al principio de ellas, coadyuvaría al mantenimiento del suspense durante toda la representación del teatro breve o, en su caso, a retomar el argumento con el interés y expectación del público.

${ }^{30}$ L. F. de Vega Carpio (1993c), pp. 32-34. 


\begin{tabular}{|c|c|}
\hline Alberto & Es una santa. \\
\hline Eufrasia & ¿Es posible? \\
\hline Alberto & $\begin{array}{l}\text { A lo menos, por de fuera. } \\
\text { Pero, al fin, ella me enfada; } \\
\text { creed que verla no puedo; } \\
\text { donde estoy la tengo miedo; } \\
\text { es muy necia y porfiada; } \\
\text { razonable talle tiene, } \\
\text { pero es muy soberbia y loca. }\end{array}$ \\
\hline Guillermo & $\begin{array}{l}\text { Cerrar las tiendas nos toca, } \\
\text { Pierres, que la noche viene. }\end{array}$ \\
\hline Pierres & Ya bien nos podemos ir. \\
\hline Eufrasia & ¿Tan mala es vuestra mujer? \\
\hline Alberto & $\begin{array}{l}\text { Es mala para querer } \\
\text { y buena para vivir, } \\
\text { es honrada y no es muy bella. }\end{array}$ \\
\hline Eufrasia & $\begin{array}{l}\text { (¡Por Dios, sufrirlo no puedo! } \\
\text { ¡Descúbrome!) }\end{array}$ \\
\hline Alberto & $\begin{array}{l}\text { ¡¡Paso, quedo! } \\
\text { ¡Juraré que estoy con ella!) } \\
\text { Mujer, ¿sois vos? }\end{array}$ \\
\hline Teodora & Yo, también. \\
\hline Isidro & ¿Eres tú Teodora? \\
\hline Teodora & Sí \\
\hline Isidro & Que nunca te conocí. ${ }^{31}$ \\
\hline
\end{tabular}

También es muy frecuente en las tipologías el descubrimiento de incidentes o situaciones, pero nos parece revelador que, en ocasiones, prospectivamente, el suceso reconocido no haya acontecido a pesar de que exista la certeza de que tendrá lugar en el futuro, incluida la posthistoria de la comedia. Un ejemplo de este tipo de anagnórisis es el que se produce al final de La serrana de La Vera: don Juan sale a escena con una provisión real (es el elemento simbólico que otorga la certeza de su realización en el futuro) en la que se perdona a Leonarda, la serrana, a quien iban a matar. Se produce, igualmente, una peripecia, pues hay un cambio de fortuna para el personaje. Como no podía ser de otra forma, Leonarda siente vergüenza de sus actos y se arrepiente. Es una anagnórisis también para el público, que quizás esperaba el ajusticiamiento de la serrana por sus malas obras anteriores:

$$
\begin{aligned}
& \text { (Entra don Juan con una provisión). } \\
& \text { D. Juan } \quad \begin{array}{l}
\text { Este día, } \\
\text { quedará desobligada }
\end{array}
\end{aligned}
$$

${ }^{31}$ L. F. de Vega Carpio (1993b), pp. 387-388. 


\begin{tabular}{|c|c|}
\hline & $\begin{array}{l}\text { serrana, la prenda mía. } \\
\text { ¡Teneos al Rey! }\end{array}$ \\
\hline Fulgencio & ¿Quién es? \\
\hline D. Juan & $\begin{array}{l}\text { Quien trae esta provisión, } \\
\text { para que libre me des } \\
\text { a Leonarda. }\end{array}$ \\
\hline Carpio & $\begin{array}{c}\text { Y es razón } \\
\text { que me des, don Juan, tus pies. }\end{array}$ \\
\hline D. Juan & $\begin{array}{l}\text { Sus manos voy desatando, } \\
\text { perdónala el Rey por mí. }\end{array}$ \\
\hline Fulgencio & La provisión voy mirando. ${ }^{32}$ \\
\hline
\end{tabular}

El reconocimiento de objetos personales, incidentales o simbólicos en anagnórisis por un destinatario desencadena una serie de consecuencias que están relacionadas con algunos de los constituyentes de las comedias: la acción, los personajes, los temas, los recursos compositivos o el significado. Esas relaciones de causa y efecto permiten ofrecer clasificaciones de la agnición en función de sus consecuencias, como la que aparece al final de la primera jornada de Los hechos de Garcilaso de la Vega y Moro Tarfe: Gazul, escondido, escucha la conversación que sostienen Tarfe y Fátima y, en un momento dado, aparece y se enzarza con el moro, estando a punto de pelear. Evidentemente, es un tipo de anagnórisis climática muy relacionada con el recurso del enfrentamiento dual, que puede ser físico o dialéctico, como en el caso que nos ocupa:

(Sale Gazul de donde estaba).

Gazul Aunque el callar fuera sano,

el honor poco resiste,

$\mathrm{y}$ en lo que traidor dijiste,

¡mientes, cobarde villano!

(Echan mano a las espadas).

Tarfe Huélgome que no dirás, Gazul, que ha sido en tu ausencia.

Fátima Delante de mi presencia es mal hecho no haya más.

Tarfe Fátima, todo el amor no vale un mínimo agravio.

Fátima ¡Ay, Gazul, sé tú más sabio; refrena el brazo, señor! ${ }^{33}$

En cualquier caso, Lope de Vega, conocedor de las polémicas sobre la concepción de ideas aristotélicas (y, entre ellas, la anagnórisis como descubrimiento de la ver-

${ }^{32}$ L. F. de Vega Carpio (1993a), p. 97.
${ }^{33}$ L. F. de Vega Carpio (1993c), p. 15. 
dad dramática), fue capaz de integrar en sus comedias los distintos tipos de reconocimientos que postuló el filósofo y que, otros, matizaron.

\section{Hacia una conclusión}

La Poética de Aristóteles empezó a extenderse en la Edad Media pero, con las funciones de comentario, discusión y renovación que ejercieron los tratadistas del Siglo de Oro (en el siglo XVI, sobre todo italianos), los preceptos del Estagirita se intentaron aplicar a la literatura como nunca antes había sucedido.

No todas las poéticas del Siglo de Oro trataban la anagnórisis, pero las que lo hacían se dedicaban a glosar los escritos del filósofo griego y, en ocasiones, a teorizar y a afirmar preceptos que él nunca postuló. Los principales ejes de discusión fueron los siguientes:

- Eje conceptual: Se discutía, fundamentalmente, si la anagnórisis llevaba aparejada en las fábulas, o no, la peripecia. Cinthio opinaba que no, Minturno que sí. Piccolomini afirmó que Aristóteles había dicho que todos los tipos de agnición suponían un cambio de fortuna, mientras que este únicamente escribió que eran mejores los que estaban acompañados por la peripecia. Tasso, por otro lado, desafió al filósofo griego y promulgó que las fábulas que no tenían anagnórisis no tenían por qué ser simples, como decía el autor heleno.

- Eje tipológico: En general, los comentaristas aristotélicos respetaron la clasificación que el griego realizó de la anagnórisis, aunque hubiera errores como el de González de Salas. Sin embargo, teóricos como Castelvetro o López Pinciano propusieron clasificaciones paralelas, que en algunos casos completaban esa imprecisión que Robortello achacó al Estagirita.

- Eje de aplicación: Mientras que Aristóteles afirmó, como entendió Piccolomini, que aquella anagnórisis que conllevaba cambio de fortuna desde la verosimilitud de la fábula era la mejor, varios preceptistas italianos discutieron esta afirmación, como Tasso.

Con todo, estas polémicas llegaron muy debilitadas a la etapa del destierro de Lope de Vega. En general, en esta época, se entendía que las posteriores clasificaciones de la anagnórisis que realizaron los comentaristas neoaristotélicos eran matizaciones y que la peripecia solía acompañar a la agnición. Prueba de la finalización de las polémicas es que Lope únicamente se limitó a recomendar los cambios de fortuna y reconocimientos en las comedias, sin entrar en las discusiones antedichas.

Para finalizar, es necesario recordar que Aristóteles solo trató de la tragedia en su Poética, y que la aplicación de los preceptos de la anagnórisis (como otros) a la comedia se debe, en su origen, a uno de los primeros comentaristas italianos, Robortello, cuyo postulado fue aceptado por los teóricos posteriores. 


\section{OBRAS CITADAS}

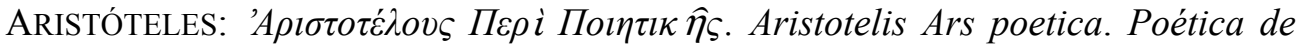
Aristóteles, Madrid, Gredos, 1988.

CASCAles, Francisco: Tablas poéticas, del licenciado Francisco Cascales. Dirigidas al Excelentissimo Señor Don Francisco de Castro, Conde de Castro, Duque de Taurisano, Virrey, y Capitan general del Reyno de Sicilia, Murcia, Luis Beros, 1617.

Castelvetro, Ludovico: Poetica d'Aristotele vulgarizzata e sposta, Roma/Bari, Laterza, 1978-1979.

CinTHIO, Giovambattista Giraldi: Discorsi di M. Giovambattista Giraldi Cinthio nobile ferrarese, e secretario dell'illustrissimo et eccellentiss. duca di Ferrara intorno al comporre de $i$ Romanza, delle Comedie, e delle Tragedie, e di altre maniere di Poesie, Venecia, Gabriel Giolito de Ferrari et fratelli, 1554.

GONZÁLEZ DE SALAS, Jusepe Antonio: Nueva idea de la tragedia antigua o Ilustración última al libro singular de Poética de Aristóteles Stagirita, Madrid, Francisco Martínez, 1633.

Horacio: Arte Poética, Cáceres, Servicio de Publicaciones de la Universidad de Extremadura, 1998.

LÓPeZ PInCIAno, Alonso: Philosophia antigua poética, Madrid, Thomas Iunti, 1596.

MinTuRno, Antonio Sebastiani: De poeta, ad Hectorem Pignatellum, Vibonensium ducem, libri sex, Venecia, 1559.

: L'arte poetica del signor Antonio Minturno, nella quale si contengono i precetti Eroici, Tragici, Comici, Satirici, e d'ogni altra Poesia: con la dottrina de' Sonetti, Canzoni, ed ogni forte di Rime Toscane, dove s'insegna il modo, che tenne il Tetrarca nelle sue opere. E si dichiara a'suoi lueghi tutto quel, che da Aristotele, Orazio, ed altri Autori Greci, e Latini è stato scritto per ammaestramento de Poeti, Nápoles, Stamperia di Gennaro Muzio, 1725.

PiCCOLOMINI, Alessandro: Annotationi nel libro della Poetica d'Aristotele; con la traduttione del medesimo Libro, in lingua Volgare, Venecia, Giovanni Guarisco, 1575.

Robortello, Francesco: In librum Aristotelis de Arte Poetica explicationes. Qui ab eodem Authore ex manuscriptis libris, multis in locis emendatus fuit, ut iam difficillimus, ac obscurissimus liber à nullo ante declaratus facile ab omnibus possit intelligi, Florencia, In Officina Laurentii Torrentini, 1548.

SÁNCHEZ ESCRIBANO, Federico y Alberto Porqueras Mayo: Preceptiva dramática española del Renacimiento y el Barroco, Madrid, Gredos, 1971.

SCALIGero, Giulio Cesare: Poetices libri septem: I, Historicus. II, Hyle. III, Idea. IIII, Parasceve. V, Criticus. VI, Hypercriticus. VII, Epinomis. Ad Sylvium filium. Lyon, Antonium Vincentium, 1561.

TASSO, Torquato: Discorsi dell'arte poetica e del poema eroico, Bari, Laterza, 1964. 
Vega CARPIO, Lope Félix de: La serrana de La Vera, en Obras completas. Comedias, $V$, Madrid, Turner, 1993a, pp. 1-99. : Las ferias de Madrid, en Obras completas. Comedias, II, Madrid, Turner, 1993b, pp. 355-456.

: Los hechos de Garcilaso de la Vega y Moro Tarfe, en Obras completas. Comedias, I, Madrid, Turner, 1993c, pp. 1-58. : Arte nuevo de hacer comedias, Madrid, Cátedra, 2006. 